https://helda.helsinki.fi

\title{
Begging the Question Against a Peer?
}

\section{Kotilainen, Konsta}

$2021-11$

Kotilainen, K 2021 , ' Begging the Question Against a Peer? ' , Journal of Philosophical

Research , vol. 46 , pp. 307-327 . https://doi.org/10.5840/jpr2021824171

http://hdl.handle.net/10138/336228

https://doi.org/10.5840/jpr2021824171

acceptedVersion

Downloaded from Helda, University of Helsinki institutional repository.

This is an electronic reprint of the original article.

This reprint may differ from the original in pagination and typographic detail.

Please cite the original version. 


\title{
BEGGING THE QUESTION AGAINST A PEER?
}

\section{Konsta Kotilainen}

University of Helsinki

konsta.kotilainen@helsinki.fi

Published in Journal of Philosophical Research, Volume 46

Author's Accepted Manuscript

DOI: $\underline{10.5840 / j p r 2021824171}$

Online First: August 25, 2021

\begin{abstract}
A dialectical conception of justification helps conciliationists about peer disagreement establish the symmetry considerations on which their account is premised. On this conception, appeals to personal or hidden forms of evidence fail to provide a symmetry breaker that would allow one to dismiss a conflicting peer opinion. Furthermore, the act of citing the same evidence repetitively tends to illegitimately beg the question against the peer, no matter how accurate one's own overall assessment of this evidence. However, the dialectical conception of justification does not automatically vindicate conciliationism. In many of the most interesting cases of peer disagreement there are vast bodies of dialectically sharable evidence that can ultimately provide enough nonquestion-begging epistemic resources to settle the dispute, even if appealing to those resources violates the independence requirement - a further premise of conciliationism. Absent modifications to the independence requirement, it would therefore be premature to embrace conciliationism.
\end{abstract}

KEYWORDS: Peer disagreement, question-beggingness, dialectical justification, epistemic contextualism, independence requirement, skepticism 


\section{ON THE EPISTEMIC SIGNIFICANCE OF PEER DISAGREEMENT}

Should the disagreement that I and my "epistemic peer" ${ }^{1}$ have lead us to suspend our conflicting judgments about the issue under dispute? Should our difference of opinion about the truth of a proposition at least reduce our confidence in our respective beliefs about it? These questions have been central to the contemporary literature on the epistemology of disagreement. Initially, the discussion concentrated primarily on religious beliefs (Van Inwagen 1996; Feldman 2007), but subsequently epistemologists have bravely begun to examine the status of political, ethical, and more broadly philosophical beliefs. ${ }^{2}$ It is now widely acknowledged that the epistemology of peer disagreement could potentially have skeptical consequences for all controversial fields of inquiry (including many empirical sciences and the social sciences), and, consequently, undermine at least some traditional forms of expertise in these fields (Lackey 2018). It is therefore not difficult to see why this debate could be highly pivotal from the point of view of the epistemology (and methodology) of these fields: widespread disagreement within them poses a very live skeptical challenge that cannot be left unanswered. ${ }^{3}$

The bulk of the views on the epistemic significance of peer disagreement fall into roughly two camps. In the first camp, philosophers such Richard Feldman (2007), Adam Elga (2007), and David Christensen (2007, 2009, 2011 and 2013) endorse a conciliatory position. They suggest that peer disagreement provides higher-order evidence that considerably bears on how confident we should be in our own respective beliefs about the issue under dispute. It is this conciliationist view that could force us into even a form of local skepticism, namely skepticism about matters of controversy (Christensen 2007; Enoch 2010; Kornblith 2013; Lammenranta 2011a).

Strong formulations of conciliationism, most prominently the Equal Weight View (EWV), require one generally to "split the difference" with one's peer (Elga 2007). While not all conciliationists are prepared to go this far $^{4}$, all agree that sticking to one's initial position in the face of peer disagreement without reasons "independent" from the initial basis for the belief seems epistemically suspicious and even intellectually arrogant. In the literature, this intuition has been formulated into a so-called independence requirement which insists that "in evaluating the epistemic credentials of another person's belief about $\mathrm{p}$, in order to determine how (if at all) to modify one's 
own belief about $\mathrm{p}$, one should do so in a way that is independent of the reasoning behind one's own initial belief about p" (Christensen 2009: 758).

In order to support the independence requirement, the conciliationists appeal to several symmetry considerations. To be precise, it seems to me that they have to invoke and motivate at least three such considerations in order to rule out different forms of steadfast responses to peer disagreement (see below). First, a rather elementary symmetry consideration suggests that peers should treat each other's views as equally valid, unless they have substantial reasons not to do so. The mere fact that an argument is mine fails to give me any justification to favor it over your argument - you can make an obvious symmetrical claim to the effect that your argument is correct because it is yours. $^{5}$

Second, an evidential symmetry consideration is needed to guarantee that no kind of evidence to which we have asymmetrical access, or evidence that affects our belief formation differently, could justify a steadfast response. Third, a judgmental symmetry consideration needs to be invoked in order to ensure that there are no differences in the quality of evidence assessment that could open up room for rational disagreement. ${ }^{6}$ As I will discuss below, the latter two of these symmetry considerations are, to some rough extent, built into the very definition of epistemic peerage: "epistemic peers" are stipulated to be more or less equally reliable assessors of evidence and to share approximately the same evidence.

Conciliationists have also been inclined to defend a so-called uniqueness thesis according to which any evidential situation allows for only one maximally rational doxastic attitude towards a proposition at a time. However, because insisting on this thesis is probably not necessary for those who wish to defend a conciliatory view (Christensen 2009), the symmetry considerations and the independence requirement seem jointly sufficient to ground conciliationism. Because neither the three symmetry considerations nor the independence requirement alone would seem to be enough to establish the sort of conciliationism defended by the philosophers in the first camp, one can view all of them as genuine premises of the conciliationist position.

Philosophers in the second camp, such as Thomas Kelly (2005, 2010 and 2013), Michael Bergmann (2009) and Ernest Sosa (2010) reject conciliationism. They maintain that in a great number of (both ordinary and intellectually interesting) cases one can 
have good reasons to retain much confidence in one's initial position despite one's awareness of peer disagreement. In other words, they argue for steadfast (or nonconciliatory) views. Sosa (2010), among others, challenges conciliationism by claiming that I am in fact very rarely in a position to consider anyone as a strict epistemic peer if he or she is required to share my evidence. Importantly, Sosa points out that it might be impossible in principle to fully disclose all the relevant evidence and that I therefore almost always possess epistemically powerful evidence that my opponent lacks. In the same spirit, Jennifer Lackey (2010: 310) identifies "personal information" - evidence that I have about my own cognitive functioning, experiences and intentions which my opponent cannot access - as a further reason for why steadfastness in the face of disagreement could be epistemically rational in some cases. ${ }^{7}$ In other words, both Sosa and Lackey (as well as Bergmann) claim to isolate symmetry breakers that challenge conciliationism by undermining primarily the evidential symmetry on which the view is grounded.

Kelly (2010 and 2013) rejects conciliationism on different grounds. His core argument is that the conciliatory views throw away substantive (first-order) evidence by letting mere observations of peer disagreement (a form of higher-order evidence) be decisive in evaluations of who behaves epistemically rationally. In Kelly's view, it is the appreciation of total evidence (first-order evidence + higher-order evidence) that matters for the epistemic rationality of beliefs, but the independence requirement embraced by the conciliationists wrongly makes appeals to the correct assessment of one's total body of evidence appear suspicious. In other words, Kelly seeks to reject conciliationism by breaking the judgmental symmetry, which leads him to argue against the independence requirement as well.

In what follows, I will first dwell a bit deeper into these two different variants of non-conciliationism (Sections II and III). I will then draw on Markus Lammenranta's (2011a; 2013) approach and suggest that a dialectical conception of justification goes a long way towards motivating the three symmetry considerations (Section IV). Finally, however, I will offer reasons to challenge the independence requirement even if justification is conceived dialectically (Section V). I will conclude by summarizing the key lessons why a conciliatory response to peer disagreement is thus not always rationally mandated even if genuine evidence is (taken to be) of a sharable sort (Section VI). 
The main argument of this paper is that even if we were to view justification as a dialectical matter, conciliationism would not thereby be vindicated. This argument is important for two related reasons. First, it contrasts with the assessment of philosophers advocating a dialectical version of conciliationism or even Pyrrhonian skepticism about controversial issues, including Lammenranta (2011a; 2011b; 2013) and Diego Machuca (2013; 2015). Second, and more strongly, because a dialectical defense of conciliationism is arguably the most promising defense of the position on offer (as suggested also by King 2012), we have a tentative reason to suspect that (far-going) conciliationism is indefensible in all of its existing forms. As explained towards the end of the paper, peer disagreement about even deeply controversial matters can, on certain conditions, be epistemically rational.

\section{IN SEARCH OF EVIDENTIAL SYMMETRY BREAKERS}

Insofar as the "elementary" symmetry consideration, which implies that one's own view does not enjoy any (prima facie) privileged status over the views of others, is seen to be beyond reasonable doubt, philosophers defending steadfastness face a choice between three strategies: they have to reject either the evidential or the judgmental symmetry between the peers, or they have to reject the independence requirement alone. The two first strategies have been much more popular than the third option: it has been suggested that peers could possess evidence of different quality or quantity. Or, if there are no evidential differences, one of them could do better at assessing the evidence at least on the occasion of the specific dispute in which they are engaged. Interestingly, both of these strategies aimed at challenging conciliationism might seem to violate the very definition of epistemic peerage - were epistemic peers not supposed to be precisely those individuals who do not differ in these two respects?

However, in most definitions, "epistemic peers" are in fact stipulated to possess only roughly the same evidence and to be only approximately as capable in assessing evidence. Some philosophers have defined the term more strictly and come close to insisting on exact parity in both respects. One could, of course, go on to eliminate all possible epistemologically relevant asymmetries between peers by stipulating epistemic peerage in a way that does not leave room for them. However, this move would grant only a trivial victory to the conciliationist: without any remaining differences in the 
epistemic basis of beliefs, either splitting the difference in the degrees of confidence or suspension of judgment would clearly be called for. I agree with Lackey (2010: 311) that we ought not to be interested in epistemic clones in hyper-idealized scenarios of disagreement but rather focus on epistemic peers engaged in real-world disputes (see also King 2012). Whereas epistemic clones hardly exist in real life, peers sharing roughly the same evidence, training and cognitive abilities abound.

The standard rough definition of epistemic peerage therefore retains an array of real-world asymmetries between peers while it simultaneously takes them to be more or less on a par in terms of their cognitive ability and the amount and quality of evidence they possess. In effect, the proponents of steadfastness argue that at least one kind of the remaining asymmetries - not ruled out by the definition of peerage - is epistemologically relevant. Moreover, at least one kind of asymmetry adequately explains why a steadfast response to peer disagreement could be appropriate in at least some cases of interest. While it is clear that most asymmetries between peers are not potential candidates for a symmetry breaker, some of them are.

In this section, I will outline arguments by Sosa, Lackey and Bergmann that appeal to asymmetries in particular types of evidence. In other words, they claim to find evidential symmetry breakers between peers that explain why (drastic) belief revision is not always called for. This move represents the first kind of steadfast strategy popular in the literature.

\section{II.A. HIDDEN AND UNDISCLOSABLE EVIDENCE}

Instead of a single argument, Sosa (2010) in fact provides a set of considerations against conciliationism. First, he usefully reminds us that much of disagreement in controversial areas of inquiry is merely verbal, resulting from all sorts of misunderstandings concerning the meanings of expressions. Second, Sosa questions the independence requirement by arguing that we sometimes can legitimately downgrade our peer's opinion on the basis of our disagreement (see Section III). Third, he stresses how "deeply hidden and undisclosable" our reasons to believe propositions often are (2010: 296). It is this last insight that concerns us in this section.

What does Sosa mean by hidden and undisclosable evidence? Primarily, he seems to have in mind evidence that is either totally "inscrutable" or at least "sufficiently hard 
to uncover" (2010: 290). Such evidence cannot be brought to the table and scrutinized because we either lack access to it or because it is "too subtle or complex to be noticed and detailed fully" (2010:290). Sosa gives several examples of cases where we believe something but are unable to fully disclose the evidence supporting our belief: "Why do we think that our math teacher in high school was named Mrs Hanson?" or "Why do we think there are stars in the sky?". These questions, despite their apparent simplicity, turn out to be surprisingly hard to answer if they are taken seriously (2010: 290-291).

On the basis of his examples, Sosa concludes that "the idea that we can always or even often spot our operative 'evidence' for examination is a myth" (2010: 291). According to Sosa, there are a number of reasons why the operative evidence standardly cannot be fully disclosed, even in addition to its complexity and subtlety. These reasons range from constraints of human memory capacity to the contingent effects that upbringing and social relations have on belief formation.

Sosa's discussion bears directly on the epistemology of peer disagreement. If reasons are standardly hidden and undisclosable, and if they, as Sosa maintains, can be "epistemically effective" despite being "dialectically ineffective", reasonable disagreement is standardly possible. If we cannot disclose all of our evidence even in many everyday cases, we certainly cannot disclose it in truly complicated scientific or philosophical contexts either.

Effectively, hidden evidence asymmetrically possessed by peers is thus suggested to provide an evidential symmetry breaker that can justify a steadfast response to peer disagreement. For our purposes, it is important to note how vital it is to Sosa's argument that a reasonable belief can "properly remain unvoiced and undefended" (2010: 292). If this was not the case, hidden and undisclosable evidence could not be relevant for the justification of beliefs. I will return to this observation in Section IV.

\section{II.B. PERSONAL INFORMATION}

Whereas Sosa argues that a full disclosure of evidence is in most cases impossible in the first place because peers cannot really spot all the operative evidence, Bergmann (2009) and Lackey (2010) set out to discuss the prospects of rational disagreement assuming that all the evidence has been (verbally) shared. Bergmann (2009: 339) notes that even after such hypothetical full disclosure of evidence, the peers do not possess exactly the same evidence because "reporting their apparent insights to each other is not the same 
as giving those apparent insights to each other." Based on this asymmetry, he goes on to defeat the ethical egoist and the moral nihilist by maintaining that he has a genuine insight that (e.g.) killing young children by torturing them is wrong. ${ }^{8}$ If Bergmann indeed can win arguments with egoists and nihilists in this way, he would also win the (second-order) argument with the conciliationists.

Lackey (2010) provides a more complete treatment of the epistemic significance of the kind of evidence to which Bergmann alludes. She defines "personal information" as the evidence that "one has about the normal functioning of one's own cognitive faculties" that is inaccessible to everyone else (2010: 310). I know that I am not depressed or intoxicated (or lying) whereas I can never be similarly certain about you. You can, of course, tell me that you are not, but the evidence that such a testimony provides me about your mental states does not seem to amount to the sort of strong direct evidence that I have about my own mental states (Lammenranta 2011a). ${ }^{9}$

It thus appears that such personal evidence ${ }^{10}$ can serve as a further evidential symmetry breaker that explains why I should not always (or even usually) take your view as seriously as I take mine. The role suggested for personal evidence is, in this context, similar to Sosa's undisclosable evidence: both serve to explain why reasonable peer disagreement might after all be possible. It is nevertheless important to notice that there are some differences between undisclosable and personal forms of evidence. Whereas the former type of evidence is something that cannot even be reported, the latter can be. I often cannot report all the reasons that led me to form a particular belief since I am unable to access some of them even myself. In contrast, I do have direct access to my personal evidence and can therefore report it to you. I can testify that I think I am not drunk or exhausted, but I cannot testify all the reasons why I think there are stars in the sky. In other words, a specific piece of personal information is evidence to which one party in a dispute has direct access, but the other parties at most testimonial access. In contrast, a piece of deeply hidden evidence cannot be accessed directly by any party, although it still affects the beliefs of one of the parties through its causal impact on his or her belief formation.

Despite their different natures, both hidden and personal forms of evidence are potential candidates for evidential symmetry breakers, and, thereby, both constitute a challenge to the conciliationist. In Section IV, we will see that this challenge proves 
effective only on the condition that we accept an individualistic conception of justification of beliefs. I will now turn to discuss whether there are potential symmetry breakers of the judgmental sort.

\section{ASYMMETRICAL ASSESSMENT OF TOTAL EVIDENCE?}

In this section, I will describe Kelly's much-discussed view which, instead of singling out any particular type of evidence, focuses on ways in which total evidence could justify one view over another. Instead of concentrating on asymmetries in evidence itself, Kelly in fact suggests how judgments about what proposition the total evidence supports could be epistemically asymmetrical - some of them more accurate than others. Indeed, in Kelly's examples the evidence is often literally shared, but one party to the dispute misjudges it. In other words, whereas especially Sosa and Lackey focus on evidential asymmetry, Kelly's emphasis is on judgmental asymmetry. His account thus represents the second kind of steadfast strategy that has gained some currency in the literature. ${ }^{11}$

Kelly $(2010 ; 2013)$ agrees with the conciliationists that awareness of a peer's disagreeing view provides evidence for the proposition that I might be mistaken. However, he maintains that in complicated intellectual disputes such evidence should normally play only a minor (even if varying) role vis-à-vis the available first-order evidence. Hence, in many such cases Kelly's Total Evidence View (TEV) recommends giving the most weight to the original substantive evidence. In this picture, higher-order evidence does supplement first-order evidence. But the awareness of disagreement tends to provide decisive evidence only in the kind of relatively simple thought experiments that the conciliationists, in Kelly's view mistakenly, take to support their general conclusion. In a standard example, if I believe that our restaurant bill should be so divided that each of us pays 43 dollars, but you (generally being an equally reliable calculator as me) believe that each should pay 45 dollars, we should both suspend judgment about the correct amount until we check our math (Christensen 2007). In Kelly's view, however, this conclusion follows only because in this "simple restaurant case" there is no substantive body of first-order evidence over and above the higherorder evidence provided by the disagreement. Judgmental asymmetries have no chance to arise. 
Kelly's doubts about judgmental symmetry lead him to reject the independence requirement (Kelly 2013). ${ }^{12}$ He maintains that the entire inspiration for it - the idea that "dogmatic" responses to peer disagreement should be uniformly discouraged - ought to be questioned (see Christensen 2011). This is because Kelly thinks that dogmatism should not be seen as a "formal vice": it is not always and everywhere incorrect to beg the question against a peer. Instead of purely formal considerations, the plausibility of a dogmatic response to peer disagreement should, in his view, depend on one's total evidence. (2013: 47-52).

Kelly is not the sole critic of the (universal applicability of the) independence requirement. Resembling Kelly's account, Sosa (2010) suggests that we sometimes can legitimately downgrade our peer's opinion on the basis of our disagreement. He supports this conclusion by reflecting on Moore's famous disagreement with a skeptic where Moore (in Sosa's view not inappropriately) begs the question against the skeptic. ${ }^{13}$ Other instances where Sosa believes we can ignore peer disagreement by an appeal to the very issue under dispute include "self-evident" cases (if someone did believe that $2+2$ would not equal 4 , we could safely dismiss her opinion as crazy), as well as some harder disputes (such as a revised restaurant case where mental calculations can be re-checked with calculators).

Bergmann (2009: 339) also provides some reasons for thinking that it is sometimes legitimate to appeal to the disputed first-order evidence in order to reject a disagreeing peer opinion. If the initial belief about a proposition is a "strongly justified" response to the first-order evidence, it will take a very powerful defeater to defeat that belief. Bergmann suspects that in interesting cases, mere disagreement usually fails to provide a defeater strong enough. The shared belief of peers that there generally is a "rough equality in intellectual virtue" between them does not imply that they would be equally reliable about the particular issue under dispute (2009: 340). According to Bergmann, both parties can then be at least internally rational in sticking to their initial beliefs.

It bears emphasizing that Kelly, and also Sosa and Bergmann, are led to reject the independence requirement at least partially because of the doubts they have over (a wide applicability of) the condition of judgmental symmetry. I will now turn to assess to what extent the conciliationist premises can be motivated and on which grounds. 


\section{THE DIALECTICAL ROUTE TO MOTIVATE THE SYMMETRY CONSIDERATIONS}

Lammenranta (2011a; 2013) points out that most contemporary conciliationists fail to provide an adequate answer to the steadfast critique that appeals to the existence of asymmetric personal or even simple perceptual evidence. ${ }^{14}$ While he shares the main intuitions supporting conciliationism, Lammenranta argues that "individualistic" accounts of justification, to which conciliationists also tend to be committed, are unable to explain those intuitions satisfactorily. On these individualistic accounts, the justification of a person's belief depends solely on the other beliefs, experiences, cognitive processes or abilities of the individual in question. Importantly, the justification of the belief therefore does not depend on the beliefs of other people in any direct way. However, the beliefs the individual may have about the beliefs of others can also affect the justification of her belief on individualistic accounts. If she believes that (1) she has an epistemic peer and (2) the peer disagrees with her, this pair of beliefs can potentially defeat the justification of her original belief in an indirect way. By contrast, peer disagreement in itself is irrelevant to the belief's justification. If the person does not believe that a peer disagrees with her, the disagreement does not provide a defeater against her belief (Lammenranta 2011a: 4-5).

Despite their many crucial differences, most contemporary accounts of justification are individualistic in the above sense. On internalist views, justification has been taken to depend on the evidence, reasons, experiences and mental states an individual is aware of, can access by reflection, or at least possesses (see e.g. Conee and Feldman 2001). On externalist views, justification has traditionally been taken to depend, for instance, on the reliability of an individual's psychological process (see e.g. Goldman 1986: 81-121) or intellectual faculty (see e.g. Sosa 1991: 131-146). In other words, both internalist and externalist accounts have tended to be individualistic in the sense that they have focused on non-social (largely mental and cognitive) factors. What is relevant for the purposes of this paper is that this kind of individualism has characterized the most widely discussed forms of internalism and externalism, including evidentialism and reliabilism (Lammenranta 2011a; 2013: 52-53; see also Wieland 2013). ${ }^{15}$ 
Lammenranta argues that an alternative "dialectical" conception of justification would fare considerably better in grounding the symmetry considerations and the independence requirement embraced by the conciliationists. According to dialectical conceptions, the justification of a belief depends on its defensibility. In Lammenranta's (2013: 61) formulation, "S is justified in believing that $\mathrm{p}$ if and only if $\mathrm{S}$ can defend $\mathrm{p}$ against appropriate challenges." For such a dialectical account to constitute a serious alternative, its proponents will need to specify at least (a) the meaning of "defend" (b) the modality of the "can", and (c) the criteria of "appropriate" challenges.

While there are different ways to fill in the details (see e.g. Rescorla 2009; Wieland 2013), for the purposes of this paper it makes sense to take inspiration primarily from Lammenranta (2011a, 2013) and related contextualist ideas. We can understand the dialectical account along the following lines:

(a) Defending $\mathrm{p}$ consists of presenting non-question-begging arguments or evidence against appropriate challenges to $\mathrm{p}$. If the opponent decisively rejects the arguments and evidence presented, they will be question-begging in the relevant sense. A defense need not be immediately successful in convincing a peer (as will be argued in Sections $\mathrm{V}$ and VI), but attempts to defend $\mathrm{p}$ against the appropriate challenges of a very stubborn peer may ultimately become question-begging and suspension of judgment may thereby be called for (until new non-question-begging defenses can be articulated).

(b) S can defend p against appropriate challenges as long as she is able, whenever appropriate challenges arise, to defend p. (In my view, S's justification for believing that $\mathrm{p}$ (at time $\mathrm{t}$ ) should not be taken to depend on her ability to defend $\mathrm{p}$ against challenges that have not arisen (by t).)

(c) Appropriate challenges to $\mathrm{p}$ should be specified with respect to contextual criteria. These criteria should be viewed as social in nature - neither of the peers alone can decide which challenges are appropriate. In everyday situations, only relatively mundane challenges tend to be taken as appropriate. Scientific contexts, on the other hand, often allow serious questioning of common-sense views. When we enter the domain of philosophy, it becomes appropriate to challenge, for instance, methodological assumptions of science itself. Within the context of specific epistemological disputes, such as the one we are engaged in here, even the challenges of a Pyrrhonian skeptic are 
appropriate. If we move on to debate Cartesian-type skeptical scenarios, the challenges of even a global skeptic are, in these particular contexts, taken seriously. In this way, the dialectical account of justification marries well with broader, and currently muchdiscussed, epistemic contextualism (Annis 1978; Ichikawa 2017; Williams 2001).

I agree with the thrust of Lammenranta's diagnosis about why dialectical justification alters the terms of the peer disagreement debate in a way favorable to a conciliationist. Below, I address why it favors the conciliationist with respect to each of the three aforementioned kinds of symmetry: elementary, evidential, and judgmental.

First, the dialectical conception implies that privileging one's own perspective purely on the basis that it is one's own perspective is generally epistemically illegitimate -this move can hardly ever be defended against challenges. But, while virtually everyone seems to accept the elementary symmetry consideration, philosophers accepting individualistic conceptions of justification may in fact face difficulties in formulating well-motivated defenses of it. Internalist accounts often allow that the strong belief, feeling, intuition or experience that people have about the correctness of their own view can act as a sort of symmetry breaker. Because I can never directly assess the extent to which you may feel "being correct", and if I have a strong sense that I really am correct, I seem entitled to my view (and you may well be entitled to yours). ${ }^{16}$ Externalist accounts claim that only differences in our reliability, however conceived, can break the symmetry. To the extent that our disagreeing intuitions about who is correct cannot both be reliably formed, at most one of us holds a justified view. While neither of us is likely to have a reliably formed view about the general superiority of one's own views, reliabilism allows that one party can reliably treat itself as at least comparatively reliable "truthometer" in the type of question at hand (as long as peers are only approximately as capable assessors of evidence). On both types of individualistic accounts, even the elementary symmetry consideration may therefore be threatened.

The second reason the dialectical conception favors conciliation is more important. Personal forms of evidence à la Lackey do not succeed in justifying a belief on the dialectical conception, whereas they seem to do so on individualistic accounts (Lammenranta 2011a: 10-11). A dialectical conciliationist can point out that appeals to forms of evidence that are not fully sharable illegitimately beg the question against the 
peer in most contexts of interest. In contrast, an individualist conciliationist cannot consistently claim that appeals to dialectically ineffective personal or perceptual evidence would be weak - for evidentialists appeals to such evidence can be powerful as such, while reliabilists additionally require that the cognitive processes and perceptory senses producing the evidence are trustworthy.

Similarly, hidden evidence à la Sosa does not cause problems for the dialectical conciliationist whereas it easily causes them for the individualist. If anything, for reasons briefly discussed in Section II, it seems that the dialectical account rules out appeals to this sort of undisclosable evidence even more firmly than it excludes appeals to personal evidence. Testimonial evidence about your mental states and perceptions adds to my evidence even on a dialectical account and perhaps could settle a dispute in some rare cases (in principle you could convince me that your mental processes are currently functioning better than mine, for instance, by reminding me that I told you that I did not sleep very well last night and by insisting that you did). In contrast, the inaccessible evidence that you have for your belief does not provide any sort of additional evidence for $m e$. The undeniable fact that it is often impossible to articulate or even recollect all the reasons one has (had) for embracing a particular position is not at all problematic for a dialectical conciliationist who takes justification to depend only on insights that one can recollect, articulate, and on demand defend.

Third, the dialectical conception of justification also takes a conciliationist far in motivating the judgmental symmetry between peers. Importantly, it does so irrespective of whether either of them has in fact judged the issue at hand correctly or not. Appealing to the argument under dispute smacks of an illegitimate move in a conversational context even when the disputants are not peers (Lammenranta 2008). If you have already studied and made up your mind about certain considerations, it seems pointless for your peer to recite them, even if, from her point of view, you have made obvious-looking mistakes of reasoning in rejecting them. This way of proceeding would, again, amount to question-begging in a dialectical sense. In a true dialectic, all views are on a par in the first instance, and it is often demanding to justifiably dismiss the opponent's challenges (although, in most contexts, not impossible). An individualistic conciliationist, by contrast, cannot appeal to dialectical considerations and must therefore accept that a judgmental asymmetry between peers, however slight, can entitle one of them to stick to their initial view. Internalist and externalist 
conciliationism seem to face this same problem as both imply that judgmental asymmetries between individuals can settle disagreements in an epistemic sense (as opposed to a dialectical sense).

The choice between different conceptions of justification thus matters enormously for how viable our candidates for a symmetry breaker are. But why should we favor a dialectical account over an individualistic one? The matter is not clear cut. Indeed, much of contemporary analytical epistemology is implicitly based on an individualistic conception of justification and some philosophers have argued against the dialectical view explicitly. For instance, Kelly (2010), Timothy Williamson (2004), and James Pryor (2000; 2004) suggest that we should distinguish between the dialectical appropriateness of appealing to certain pieces of evidence in a debate and the question of whether these pieces of evidence in fact justify our beliefs. This distinction has its attractions and it is not difficult to come up with cases in which it seems plausible to insist on it. For instance, one may probably come to know something about one's own (relatively simple) mental states purely on the basis of personal evidence. One can know that one is not in pain by straightforward introspection. It is perfectly reasonable to claim that the justification of at least this kind of belief should not depend on whether one is able to defend the belief in a debate.

On the other hand, there is a large category of beliefs whose justification does seem to depend on whether they can be publicly defended against appropriate challenges. Political views provide a paradigm example. It would strike us as totally unconvincing, and rather curious, if you claimed that you indeed have good reasons for your view on, say, global taxation, but that you just keep forgetting them in the relevant debates. Sure, it is possible to forget important reasons that indeed could justify your view if they were articulated. But as long as they remain unarticulated, they fail to justify the view at issue. Many philosophical and scientific views arguably fall into broadly this same category, although there may be exceptions.

As suggested above, a version of epistemic contextualism might provide a promising approach forward. Whereas justified political, philosophical, and scientific beliefs typically ought to be publicly defensible, there are also more "private" beliefs whose justification is not dependent on their defensibility against the challenges of 
other people. It seems reasonable that we should raise our standards of justification (and evidence) in topics amenable to interpersonal debate.

In this section, I have argued that dialectical conciliationism - as defended most explicitly by Lammenranta - can handle all the major symmetry breaker candidates proposed in the literature. Because dialectical conciliationism may thus be the most promising form of conciliationism on offer, it is important to examine whether it could ground the independence requirement as well.

\section{THE INDEPENDENCE REQUIREMENT AND DIALECTICALLY SHAREABLE EVIDENCE}

As explained in the introduction, the conciliationist stance on peer disagreement is premised on (i) three symmetry considerations and (ii) the independence requirement. We have seen that the dialectical conception of justification fares well in undermining proposals for a symmetry breaker, which favors conciliationism. But what about the independence requirement? Can the dialectical approach establish it, too?

To recall, the independence requirement insists that "in evaluating the epistemic credentials of another person's belief about $\mathrm{p}$, in order to determine how (if at all) to modify one's own belief about p, one should do so in a way that is independent of the reasoning behind one's own initial belief about p" (Christensen 2009: 758). ${ }^{17}$ I would like to suggest that firmly establishing this principle is not a straightforward task even if the dialectical account of justification is accepted.

The independence requirement, in the form in which it is standardly defended, is undoubtedly closely linked to the symmetry considerations. Because peers share roughly the same evidence and are more or less equally reliable at assessing it, and because neither is allowed to privilege her own view without any substantial symmetry breaker, appealing to considerations that are not independent of the initial reasoning has been seen as illegitimate. If there were even a slight difference, say, in the peers' ability to judge the merits of the type of proposals in question, one of them could have assessed the evidence better than the other(s). If that were the case, this person could legitimately appeal to the very considerations or reasoning that initially led her to form her belief. 
That is to say, if the relevant symmetry considerations are not motivated, the independence requirement automatically loses its force.

However, the independence requirement still does not seem to follow from our three symmetry considerations directly: it could be unfounded even if the considerations were motivated. In other words, the symmetry considerations are necessary but not sufficient conditions of the independence requirement.

Why aren't they sufficient? An individualist conciliationist faces difficulties in providing non-ad hoc reasons for the independence requirement because she "cannot appeal to dialectical factors, such as question-beggingness" (Lammenranta 2013: 56). She could argue that epistemically circular reasoning, especially "bootstrapping", is problematic even from an individualistic point of view and that the independence requirement is needed to rule out such reasoning as illegitimate. However, it is not entirely clear what goes wrong in epistemically circular reasoning. Both reliabilist and evidentialist accounts arguably allow easy knowledge based on epistemically circular arguments, including bootstrapping (Cohen 2002; Lammenranta 2003 and 2009; Vogel 2000 made this case against reliabilism only). An independence requirement could rule out bootstrapping, but it seems ad hoc on these accounts of justification.

Christensen (2010) seeks to motivate "bracketing" of first-order evidence also in cases of higher-order defeat that do not appear to have anything to do with disagreement, but rather with the effects that, for instance, certain drugs or sleep deprivation could have on one's ability to assess evidence. It seems intuitively plausible that an independence requirement indeed should apply in the presence of such nonsocial higher-order evidence. However, it is not clear why the independence requirement would apply in the peer-disagreement case if no other types of higher-order defeaters are present. As Christensen (2010: 206) himself notes, different types of higher-order defeaters may generate somewhat different intuitions.

While there is much to debate about the interconnections between different forms of higher-order defeat, it seems challenging for the individualist conciliationist to motivate the independence requirement in the peer-disagreement case. An account that can appeal to dialectical question-beggingness is more promising in this respect. But perhaps there is a plausible route to question the independence requirement even if the dialectical view is adopted. It seems that I can sometimes rationally retain my view by 
appealing to the reasoning behind it without in fact begging the question against my peer. Or, so I will argue.

My take is inspired by Nathan King's (2012: 254) observation that the requirement that epistemic peers should share the same evidence "is difficult to satisfy even on conceptions of evidence that are conducive to subjects having a common body of evidence". Because on the dialectical conception the disagreeing peers cannot appeal to personal or hidden evidence, the conception clearly makes it considerably easier for them to possess the same relevant evidence (and hence for their disagreement to satisfy the evidential condition for epistemic peerage stipulated at the outset). However, even if we only take arguments and other publicly sharable pieces of evidence into consideration, our evidence bases are rarely if ever entirely coexistent. In complicated and multifaceted disagreements the bodies of relevant evidence are so vast that even evidence that is in principle fully sharableis rarely, in fact, shared. I therefore tend to agree with King (2012: 255) that "in cases where the evidence surrounding the disputed topic is at least moderately complex," it is hard for peers to actually share the relevant evidence to the extent that would be required for a far-going conciliatory epistemic principle (e.g., to "split the difference") to apply in full force.

It seems that this line of argument casts some doubt over the plausibility of the independence requirement in many relevant cases of peer disagreement even if justification is understood in dialectical terms. Because as long as we do not actually share our bodies of evidence (which the dialectical view renders sharable), there should in principle be nothing suspicious in appeals to substantive considerations that are not independent of the reasonings that led to our disagreeing views.

Even if our bodies of evidence very largely overlap, but do not entirely overlap, it might be dialectically appropriate for me to cite those parts of my body of evidence that you have thus far failed to consider. While this move would violate the independence requirement, it would not necessarily beg the question against you. Instead, the independence requirement would seem to fail because not even the dialectical conception of justification, with its strict implications for acceptable types of evidence, can guarantee actual evidential symmetry. We have seen that the conception can handle all the major candidates for an evidential symmetry breaker suggested in the literature, 
but even this achievement, it turns out, is not quite enough to establish the independence requirement.

If the above suggestion about the vulnerability of the independence requirement is accepted, one might inquire what happens at a point in time when neither of the peers can any longer think of new arguments and other considerations to cite. Would the independence requirement not start to apply at that point? I believe that it indeed would. However, there are some reasons to doubt whether such a time might, in fact, ever arrive (and if it did, whether it would last very long). The main reason to think that all the relevant evidence is almost never fully shared is that the bodies of potentially relevant evidence are even vaster than the bodies of currently available evidence. Even if the peers do their best to share all the evidence that they at any given time possess, there usually are considerations that they are in the process of developing further, new observations that they have only recently made, and (thought) experiments that they have just carried out.

The possibility that even the fully sharable evidence of a dialectical type might not be shared even after long time spans is not pure speculation. On the contrary, it seems to me that such an unfinished state of affairs characterizes many of the great debates in philosophy. Take, say, the mind-body problem. While the debate on it has raged for over two millennia, all positions remain contested. It is understandable that this observation has sparked skeptical concerns. However, in this case it is fairly clear that all the potentially relevant evidence has still not been shared. In fact, the bodies of evidence possessed by philosophers participating in this debate have recently been rapidly growing - thanks, for instance, to the advances in the cognitive neurosciences. Because neuroscientists and philosophers are still engaged in the very long process of sharing and making sense of their different bodies of evidence, the peer disagreements within this traditionally controversial area are not generally epistemologically irrational (at the very least, they are not guaranteed to remain irrational in the future). I believe that this lesson generalizes relatively well to at least some other great debates in philosophy. ${ }^{18}$

While there clearly are debates that seem rationally irresolvable, it is equally clear that many debates that have seemed rationally irresolvable in the past have subsequently been resolved - at least judging by the criterion that widespread peer disagreement has 
vanished and a consensus view has emerged. Disputes in what used to be called natural philosophy constitute perhaps the clearest examples of this development. Formerly purely philosophical debates about matter, space, time, life and so on have shifted, in part, to the purview of the natural sciences as arguments and methods have improved to the point that a broad consensus view has eventually formed (this is not to argue, of course, that the separation between philosophy and science would be a strict one nor that there would be no controversy left within the natural sciences - there is plenty, but perhaps not of irresolvable sort). Even if a debate has been in a standstill for a long time, and no one knows how to proceed, new considerations and findings could later revitalize the debate. With new progress, irresolvable-looking controversies could ultimately turn out to be resolvable. While philosophical aporias can be daunting, they may still not be strictly eternal, in contrast to what Rescher (2006: 75-93) seems to suggest.

If disagreeing peers can no longer think of novel evidence to cite, they face considerable pressure to suspend judgment. However, this response might still not be epistemologically mandated straightaway. Even with strictly identical evidence bases, it might sometimes be appropriate to suggest to a peer that she might not yet have fully appreciated the entire evidence base. However, even if it were legitimate to resort to this move once or twice, it would, of course, amount to question-begging if reiterated repeatedly.

Once we introduce a time dimension to the peer disagreement debate, it seems to become somewhat more challenging to defend a conciliationist position. Even if suspension of judgment is called for when evidence is fully shared and the disagreement persists, it is not clear what is rationally demanded when the process of evidencesharing is still underway - as it almost always is. A dialectical conciliationist might be tempted to suggest that one ought to suspend judgment until the issue under dispute is fully settled. There are two replies to this. First, the dialectical conception of justification, as defined in Section IV, states that justified beliefs are those that can be defended against appropriate challenges. A belief is justified as long as it can be defended. Alternative stronger versions of the conception could be formulated, of course. Second, to suggest that justified beliefs are possible only about issues that have been settled would arguably go too far. Any version of the dialectical conception that 
implies that genuine evidence $i$ s shared, instead of being "merely" sharable, would probably fail to be a very useful conception for most of our epistemic purposes.

\section{CONCLUSIONS}

At the outset of this article, I suggested that conciliationism is based on three symmetry considerations (the elementary, the evidential, and the judgmental), as well as on the socalled independence requirement (which is grounded on the symmetry considerations but does not follow from them directly). I noted that if these premises stand up to scrutiny, there is little room for steadfastness. Conversely, to the extent that they can be effectively challenged, non-conciliatory responses to peer disagreement seem reasonable.

Following Lammenranta (2011a; 2013), I then argued that in order to motivate the symmetry considerations, a conciliationist would be well advised to adopt a dialectical conception of justification instead of an individualistic one. A dialectical conception may in fact offer the only coherent route to explain why question-begging arguments usually fail to impress.

By eliminating the standard candidates for a symmetry breaker, the dialectical conception of justification takes us very far in establishing a conciliationist view. However, even if the dialectical view is accepted, a conciliatory response to peer disagreement might not always be rationally mandated. This is because not even dialectical considerations seem to be enough to fully motivate the independence requirement. Although they render evidence sharable and dialectically ineffective judgment futile, they still allow one to appeal to those parts of one's first-order body of evidence that one has not yet fully shared, and arguably even to those parts of one's reasoning that one's peer has not yet fully appreciated. These moves do not seem to beg the question against the peer in any illegitimate sense (at least not straightaway or in every context), but they do violate the independence requirement.

It therefore seems to me that it is sometimes legitimate to maintain that the dialectically available and sharable total evidence on balance supports one's view over the disagreeing view of one's peer. Clearly, it would be dialectically ineffective to keep citing the same pieces of evidence over and over again. But it would not necessarily be 
ineffective to appeal to considerations and arguments that the peer might still not have taken fully on board or might not have assessed entirely satisfactorily - even if those considerations are not independent of the "reasoning behind's one's own initial belief about p" (Christensen 2009: 758). ${ }^{19}$

Finally, and least contentiously, there would be nothing epistemically suspicious in keeping trying to find truly novel pieces of evidence that might, eventually, succeed in convincing one's peer (of course, they could just as well turn out to show that she was right all along). ${ }^{20}$ Pursuit of new evidence of which no party to the dispute is initially aware, does not violate the independence requirement.

In sum, since a dialectical conception of justification motivates all the relevant symmetry considerations, it makes a dialectical form of conciliationism look attractive. Even dialectical conciliationism seems to lack the resources to establish the independence requirement, however. Because not all violations of the independence requirement illegitimately beg the question against a peer, the chance of epistemically rational peer disagreement cannot be ruled out. ${ }^{21}$

\section{BIBLIOGRAPHY}

Annis, David B. 1978. "A Contextualist Theory of Epistemic Justification.” American Philosophical Quarterly 15: 213-219.

Bergmann, Michael. 2009. "Rational Disagreement after Full Disclosure.” Episteme 6: 336-353.

Carter, Adam. 2011. "Radical Skepticism, Closure, and Robust Knowledge.” Journal of Philosophical Research 36: 115-133.

—. 2016. “Group Peer Disagreement.” Ratio 29: 11-28.

Christensen, David. 2007. "Epistemology of Disagreement: the Good News." The Philosophical Review 116: 187-217.

—. 2009. "Disagreement as Evidence: The Epistemology of Controversy." Philosophy Compass 4: 756-767.

—. 2010. "Higher-Order Evidence." Philosophy and Phenomenological Research 81: 185-215. 
—. 2011. "Disagreement, Question-Begging and Epistemic Self-Criticism." Philosophers' Imprint 11: 11-22.

—. 2013. "Epistemic Modesty Defended." In The Epistemology of Disagreement: New Essays, ed. David Christensen and Jennifer Lackey. Oxford: Oxford University Press, 77-97.

Cohen, Stewart. 2002. "Basic Knowledge and the Problem of Easy Knowledge." Philosophy and Phenomenological Research 65: 309-329.

Conee, Earl and Richard Feldman. 2001. "Internalism Defended." American Philosophical Quarterly 38: 1-18.

Elga, Adam. 2007. "Reflection and Disagreement.” Nô̂s 41: 478-502.

Enoch, David. 2010. "Not Just a Truthometer: Taking Oneself Seriously (but not Too Seriously) in Cases of Peer Disagreement." Mind 119: 953-997.

Feldman, Richard. 2007. "Reasonable Religious Disagreement.” In Philosophers Without Gods, ed. Louise Antony. Oxford: Oxford University Press, 194-214.

Goldman, Alvin I. 1986. Epistemology and Cognition. Cambridge, MA: Harvard University Press.

Ichikawa, Jonathan J (ed.). 2017. The Routledge Handbook of Epistemic Contextualism. London: Routledge.

Kelly, Thomas. 2005. "The Epistemic Significance of Disagreement.” In Oxford Studies in Epistemology, ed. Tamar Szabo Gendler and John Hawthorne. Oxford: Oxford University Press, 167-196.

—. 2010. "Peer Disagreement and Higher Order Evidence." In Disagreement, ed. Richard Feldman and Ted A. Warfield. Oxford: Oxford University Press, 111-175. —. 2013. "Disagreement and the Burdens of Judgment." In The Epistemology of Disagreement: New Essays, ed. David Christensen and Jennifer Lackey. Oxford: Oxford University Press, 31-53.

King, Nathan L. 2011. "McGrath on Moral Knowledge.” Journal of Philosophical Research 36: 219-233.

— 2012. "Disagreement: What's the Problem? Or a Good Peer is Hard to Find." Philosophy and Phenomenological Research 85: 249-272. 
Kornblith, Hilary. 2013. “Is Philosophical Knowledge Possible?” In Disagreement and Skepticism, ed. Diego E. Machuca. London: Routledge, 260-276.

Lackey, Jennifer. 2010. “A Justificationist View of Disagreement's Epistemic Significance.” In Social Epistemology, ed. Adrian Haddock, Alan Millar and Duncan Pritchard. Oxford: Oxford University Press, 298-325.

—. 2018. "Experts and Peer Disagreement." In Knowledge, Belief, and God: New Insights in Religious Epistemology, ed. Matthew A. Benton, John Hawthorne and Dani Rabinowitz. Oxford: Oxford University Press, 228-245.

Lackey, Jennifer and Ernest Sosa (eds.). 2006. The Epistemology of Testimony. Oxford: Oxford University Press.

Lammenranta, Markus. 2003. "Reliabilism, Circularity, and the Pyrrhonian Problematic.” Journal of Philosophical Research 28: 311-328.

— 2008. "The Pyrrhonian Problematic.” In The Oxford Handbook of Skepticism, ed. John Greco. Oxford: Oxford University Press, 9-30.

—. 2009. "Epistemic Circularity.” In Internet Encyclopedia of Philosophy, ed. Bradley Dowden and James Fieser. https://iep.utm.edu/ep-circ/.

_. 2011a. "Disagreement, Skepticism, and the Dialectical Conception of Justification.” International Journal for the Study of Skepticism 1: 3-17.

—. 2011b. "Skepticism and Disagreement." In Pyrrhonism in Ancient, Modern, and Contemporary Philosophy, ed. Diego E. Machuca. Dordrecht: Springer, 203-215. _. 2013. "The Role of Disagreement in Pyrrhonian and Cartesian Skepticism." In Disagreement and Skepticism, ed. Diego E. Machuca. London: Routledge, 46-65. Lutz, Matt. 2020. "Explanationism provides the best explanation of the epistemic significance of peer disagreement.” Philosophical Studies 177: 1811-1828.

Machuca, Diego. 2013. “A Neo-Pyrrhonian Approach to the Epistemology of Disagreement.” In Disagreement and Skepticism, ed. Diego Machuca. New York: Routledge, 66-89.

_. 2015. "Agrippan Pyrrhonism and the Challenge of Disagreement." Journal of Philosophical Research 40: 23-39. 
Martin, N. Gabriel. 2020. "What does determining that a disagreement is not a "peer disagreement' mean?" South African Journal of Philosophy 39: 79-88.

McGrath, Sarah. 2008. "Moral Disagreement and Moral Expertise." In Oxford Studies in Metaethics, Volume III, ed. Russ Shafer-Landau. Oxford: Oxford University Press, 87-107.

2011. "Reply to King.” Journal of Philosophical Research 36: 235-241.

Pryor, James. 2000. "The Skeptic and the Dogmatist.” Noûs 34: 517-549.

—. 2004. “What's Wrong with Moore's Argument?” Philosophical Issues 14: 349378.

Rescher, Nicholas. 2006. Philosophical Dialectics. An Essay on Metaphilosophy. Albany: State University of New York Press.

Rescorla, Michael. 2009. "Shifting the Burden of Proof." The Philosophical Quarterly 59: 86-109.

Sosa, Ernest. 1991. Knowledge in Perspective: Selected Essays in Epistemology. Cambridge: Cambridge University Press.

—. 2010. “The Epistemology of Disagreement.” In Social Epistemology, ed. Adrian Haddock, Alan Millar and Duncan Pritchard. Oxford: Oxford University Press, 278-297.

Van Inwagen, Peter. 1996. "Is It Wrong, Everywhere, Always, and for Anyone, to Believe Anything upon Insufficient Evidence?" In Faith, Freedom, and Rationality, ed. Jeffrey Jordan and Daniel Howard-Snyder. Lanham: Rowman \& Littlefield, 137-154.

Vogel, Jonathan. 2000. “Reliabilism Leveled.” Journal of Philosophy 97: 602-623.

Wedgwood, Ralph. 2007. The Nature of Normativity. Oxford: Oxford University Press. Weintraub, Ruth. 2020. “A new solution to the problem of peer disagreement.” Inquiry 63: 795-811.

Wieland, Jan W. 2013. “Is justification Dialectical?” International Journal for the Study of Skepticism 3: 182-201.

Williams, Michael. 2001. Problems of Knowledge: A Critical Introduction to Epistemology. Oxford: Oxford University Press. 
Williamson, Timothy. 2004. "Philosophical 'Intuitions' and Scepticism about

Judgment." Dialectica 58: 109-153.

\title{
ENDNOTES
}

\begin{abstract}
${ }^{1}$ In most definitions, people are epistemic peers if they (i) share roughly the same evidence, and (ii) are more or less equally capable of assessing the evidence (Christensen 2007; Kelly 2010; Lackey 2010). Possible further conditions need not concern us here. For virtually all authors, epistemic peers also take each other to be equally likely to get the relevant things right (whether justifiably or not - on this distinction, see Enoch 2010; Martin 2020).
\end{abstract}

${ }^{2}$ Metaethicists had discussed the ramifications of moral disagreement prior to the epistemological debate (Machuca 2013: 66-69). McGrath (2008) developed one of the first distinctively epistemological arguments for skepticism about controversial moral beliefs (for a discussion, see e.g. King 2011 and McGrath 2011).

${ }^{3}$ Given that academic fields involve groups of researchers, puzzling questions about how conciliationism could be applied at a group level have to be addressed (see e.g. Carter 2016).

${ }^{4}$ For instance, according to Christensen (2009), conciliationism does not always mandate one to literally split the difference. In addition to being unintuitive in some cases, this principle might sometimes not even be technically possible to apply.

${ }^{5}$ This elementary symmetry consideration easily makes egocentric arguments for steadfastness look weak (however, see Wedgwood 2007: 261-262, Enoch 2010, and Williamson 2004).

${ }^{6}$ I employ the term "symmetry consideration" perhaps a bit more broadly than much of the literature. The term tends to be used in plural but it is often not specified what kinds of considerations are at stake. Based on the kind of "symmetry breakers" that have been suggested in the literature, it makes sense to speak of three corresponding symmetry considerations: the elementary, the evidential, and the judgmental.

${ }^{7}$ Lackey (2010) does not fall easily into either of the camps. Also many other authors have argued for middle positions (see e.g. Enoch 2010; Lutz 2020; Weintraub 2020). Overall, the number of philosophers who believe that there is a universally correct attitude towards peer disagreement has declined as the literature has matured.

${ }^{8}$ Bergmann suggests that those who disagree with him about killing children err because they are suffering from a "peculiar cognitive processing problem" (they may well be "internally rational" but are bound to be "externally irrational"). If this argument is correct, it is not self-evident whether the asymmetries supposed to justify a steadfast response in this case are evidential or judgmental. Intuitions can arguably be understood either as judgments or as pieces of evidence.

${ }^{9}$ Ultimately, the merits of this proposition depend on the nature of testimonial evidence. To be precise, they hinge on the "transmission of epistemic properties" thesis (Lackey and Sosa 2006: 6-7).

${ }^{10}$ I prefer the term "personal evidence" to "personal information".

${ }^{11}$ Personal evidence and perhaps also hidden evidence count as parts of total evidence in Kelly's view. However, even if they are excluded, the view does not collapse. Ultimately, this is because Kelly's account is based on judgmental rather than evidential asymmetry. There certainly is overlap between these two steadfast strategies, however.

12 Kelly (2013: 37) believes that "once one accepts Independence, Conciliationism is more or less irresistible". I would add that a strict epistemic symmetry between peers will need to be accepted as well.

13 Kelly $(2013$, 48) appeals to Moorean considerations. For a critical discussion on Neo-Moorean responses to the radical skeptic, see Carter 2011.

${ }^{14}$ Perceptual evidence is a further candidate for an evidential symmetry breaker. Whereas I can perceive things directly, I can gain evidence of your perceptions only through testimony (Lammenranta 2011a). In this respect, perceptual and personal evidence work analogously.

15 The claim is not that externalism or even internalism would be inherently individualistic positions. Externalist accounts may be broadened to encompass social factors as sources of belief (however, for instance Goldman (1986: 50) explicitly ruled out "factors external to the cognizer's psychology").

${ }^{16}$ If one counts the level of confidence that one assigns to one's belief as a type of evidence or as a factor that somehow simply accompanies a well-formed judgment, this seemingly elementary asymmetry comes very close to being either an evidential or a judgmental symmetry breaker. 
${ }^{17}$ Kelly (2013: 40) formulates the requirement slightly differently.

${ }^{18}$ Admittedly, this lesson might not carry equally well to, say, debates in politics where clear progress is not in sight. However, the possibility of future progress cannot be excluded.

${ }^{19}$ Relatedly, and more generally, it is important to acknowledge that what kinds of argumentative strategies are taken to be dialectically acceptable is, to some extent, a context-dependent matter. Whereas the rules of logic provide universal means to distinguish the formally valid inferences from the invalid ones, there hardly are universal rules of dialectical appropriateness. The dialectical view of justification could helpfully be understood against the broader framework of epistemic contextualism.

${ }^{20}$ Indeed, the search for further evidence should be encouraged also by a Pyrrhonian skeptic.

${ }^{21}$ I am grateful to Dr. Markus Lammenranta and the two anonymous referees for their detailed comments. I would also like to thank Professors Heikki Patomäki and Teivo Teivainen as well as the participants of several distinct seminars at the University of Helsinki. 